\title{
Clinical profile and outcome of obstetric ICU patients. APACHE II, SOFA, SAPS II and MPM scoring systems for prediction of prognosis
}

\author{
Pratibha Devabhaktuni $^{{ }^{*}}$, Srinivas Samavedam ${ }^{2}$, Gopal V. S. Thota ${ }^{3}$, Saraschandrika V. Pusala ${ }^{1}$, \\ Kasturibai Velaga ${ }^{1}$, Lavanya Bommakanti ${ }^{1}$, Maljini Nawinne ${ }^{1}$, Precella Thomas ${ }^{1}$ \\ ${ }^{1}$ Department of Obstetrics and Gynaecology, CARE Institute of Medical Sciences, Hyderabad, India \\ ${ }^{2}$ Department of Critical Care, CARE Institute of Medical Sciences, Hyderabad, India \\ ${ }^{3}$ Department of Anaesthesia, CARE Institute of Medical Sciences, Hyderabad, India \\ Email: ${ }^{*}$ dpdnk@yahoo.com
}

Received 25 September 2013; revised 22 October 2013; accepted 29 October 2013

Copyright (C) 2013 Pratibha Devabhaktuni et al. This is an open access article distributed under the Creative Commons Attribution License, which permits unrestricted use, distribution, and reproduction in any medium, provided the original work is properly cited.

\begin{abstract}
Objectives: To evaluate the various scoring systems, APACHE II, SOFA, SAPS II and MPM for the prediction of prognosis of the obstetric critically ill patients admitted in a well supported ICU unit. Material and methods: A prospective, observational study was conducted among all the obstetric patients admitted to the ICU between October 2011 and December 2012, during a period of 15 months. The data collected were of three categories: demographic, obstetric and ICU related. Results and Analysis: The patients admitted in the postpartum period $(n=28$, $53.84 \%)$ were more than the antenatal admissions ( $n$ $=24,46.16 \%) .32 .69 \%$ of admissions were in the third trimester. The most common mode of delivery was emergency caesarean section $(n=27 / 40,67.5 \%)$. Total caesarean deliveries were $35 / 40=87.5 \%$ in ICU patients. The mortality prediction scores were calculated for $\mathbf{4 1}$ patients only as acid blood gas analysis was not available for the rest. Patients required ventilation- $51.92 \%$, hemodialysis- $19.23 \%$, inotropic support- $38.46 \%$, blood transfusion- $50 \%$. Analysis of the statistical data for ICU parameters has shown that hospital stay $(p=0.011)$ and ventilation days $(p=$ 0.014) are significant predictors of maternal outcome. Age $(p=0.789)$, ICU stay $(p=0.701)$ and RRT $(p=$ $0.632)$ are not significant. Among the obstetric ICU admissions, hypertensive disorders of pregnancy $(30.76 \%)$ was the predominant cause followed by obstetric haemorrhage (23.07\%). Discussion: HELLP syndrome and eclampsia $(n=4,57 \%)$ were the major causes of maternal deaths with anaesthetic mishaps accounting for
\end{abstract}

\footnotetext{
*Corresponding author.
}

$29 \%(n=2)$. One $(14 \%)$ death was due to Eisenmenger's syndrome. In one case of H1N1 admitted with ARDS, caesarean section was done in MICU for worsening respiratory distress. The maternal mortality in this series of cases was $7 / 52=13.46 \%$, excluding the unavoidable cases of maternal death ( 3 cases brain dead at admission and one cardiac arrest in emergency room), our maternal mortality rate is $3 / 48=6.25 \%$. The predicted mortality as measured by all scoring systems (for 41 patients) was between $17 \%$ and $30 \%$. The observed mortality was around $17 \%$. Hence a reduction in mortality of $40 \%$ has been achieved due to intensive care. Conclusions: Leading cause of maternal mortality was HELLP syndrome. Hypertensive disorders of pregnancy were the most common cause of admission to ICU. In this study, all the scores were equally significant in predicting maternal mortality. Amongst the interventions done for these patients mechanical ventilation seems to have an influence on the overall outcome.

Keywords: Obstetric ICU; Maternal Mortality; Scoring Systems for Prediction of Mortality Rates (PMR); APACHE II; SAPS II; SOFA; MPM; Preeclampsia; HELLP Syndrome

\section{INTRODUCTION}

Maternal deaths are defined by the WHO as the death of a woman while she is pregnant or within 42 days of termination of pregnancy, irrespective of the duration and the site of the pregnancy, from any cause related to or aggravated by the pregnancy or its management but not from accidental or incidental causes [1]. Direct obstetric deaths are those resulting from obstetric complications of 
the pregnant state (pregnancy, labour and puerperium), from interventions, omissions, incorrect treatment or from a chain of events resulting from any of the above [1]. Indirect obstetric deaths are those resulting from previous existing disease or disease that developed during pregnancy and was not due to direct obstetric causes, but which was aggravated by the physiological effects of pregnancy [1].

In India maternal mortality rate is reported to be 212 maternal deaths per one lakh live births during 20072009 [2]. Critically ill obstetric patients represent an interesting group with unique characteristics, whose management is challenged by the presence of a fetus, an altered maternal physiology and disease specific to pregnancy [3]. Pregnant patients account for a small number of ICU admissions in developed countries $(2 \%)$, but they reach up to $10 \%$ or more in developing countries $[4,5]$. Two main indications for admission based on various studies are hypertensive disorders $(17.2 \%-46 \%)$ and massive haemorrhage $(10 \%-32.8 \%)$. The remainder includes medical and other problems of pregnancy (44\%) [6].

Evidence is available suggesting that the critical care issues in obstetric patients in India are different from those observed in patients in western countries. For example, studies from India have shown that rheumatic valvular heart disease, sepsis, malaria and viral hepatitis are important reasons for ICU admission during pregnancy and are also significant causes of maternal mortality [7]. In Indian obstetric ICU neurologic failure is the most common $(63 \%)$ followed by hematologic $(56 \%)$, renal $(49 \%)$, respiratory $(46 \%)$, cardiovascular $(38 \%)$ and hepatic failure (36\%) [7].

Several disease severity scoring systems have evolved for predicting mortality in ICU patients. Acute physiology and chronic health evaluation (APACHE2), simplified acute physiology score (SAPS2), sequential organ failure system (SOFA) and mortality prediction models (MPM) are some of the scoring systems that are commonly used for objectively assessing the clinical status and severity of disease of critically ill patients [8,9].

In this paper, we present the study conducted at Care Institute of Medical Sciences during a period of 15 months from October 2011 to December 2012, the critically ill obstetric patients managed in the ICU. This was a prospective observational study to evaluate the various scoring systems for the prediction of mortality rates and to present the reduction in mortality rates in a well supported ICU unit. All the patients included in the study were referrals from other hospitals and some from the districts after visiting three to four health facilities. None of the patients were booked cases at Care hospital.

\section{MATERIAL \& METHODS}

A prospective, observational study was conducted among all the obstetric patients admitted to the ICU between October 2011 and December 2012 during a period of 15 months. The protocol for the study was approved by the Ethics Committee of the hospital.

Inclusion Criteria: Subjects were included if they were admitted during pregnancy or up to 42 days postpartum requiring ICU admission.

Exclusion Criteria: Non obstetric female patients admitted to the ICU for either gynaecological or medical or surgical causes.

The admissions comprised inpatient transfers and outpatient transfers from private clinics, other multi-specialty hospitals or directly from the emergency department. The data collected were of three categories: demographic, obstetric and ICU related. Demographic data included maternal age, presence of preexisting medical or surgical problems, date of admission to the hospital, referral from any hospital (booked/unbooked). Obstetrical data included parity, gestational age at the time of the ICU admission, type of delivery, antenatal, intranatal, postnatal complications, maternal \& perinatal outcome.

For each patient, data pertaining to ICU interventions (mechanical ventilation, hemodialysis, use of central or arterial lines, blood products, inotropes, and surgical interventions) were retrieved. In addition ICU length of stay, hospital length of stay and the outcomes of all the mothers and neonates were recorded and analyzed.

The patient's disease severity was measured by APACHE II score, SOFA score, SAPS II score and MPM score for the prediction of prognosis of the obstetric patients admitted in ICU.

All the data were collected prospectively. Categorical data were displayed as percentages. Continuous data were reported as mean $\pm \mathrm{SD}$. Data were analyzed by Windostat Version 9.1 from Indostat services, Hyderabad. The Student $t$-test was used to compare mean variables in survivors and non-survivors.

A receiver operator characteristic (ROC) curve was generated for PMR of all the scores.

\section{RESULTS AND ANALYSIS}

\subsection{Demographic and Obstetric Data}

The mean age of these patients was $26.34 \pm 5.34$ years. The mean age among the survival group was $28.85 \pm$ 1.03 years and among the non survival group was 27.66 \pm 0.91 years. But no statistical significance could be attributed $(p=0.78863)$.

The majority $(73.08 \%)$ of these patients enjoyed good past health. Fourteen patients $(n=14,26.92 \%)$ had underlying diseases like diabetes, thyroid disorders, cardiac illness, sickle cell disease, tuberculosis, Hepatitis B, Hepatitis E and bronchial asthma (Table 1).

The mean gestational age was $26.37 \pm 11$ weeks. The 
Table 1. Demographic data.

\begin{tabular}{ccc}
\hline Characteristic & No. & \% \\
\hline 1) Age (Mean \pm SD $=26.34 \pm 5.34)$ & 52 & \\
2) Medical history & & \\
Diabetes & 1 & 1.92 \\
Thyroid disorders & 4 & 7.69 \\
Hypertension & 0 & 0 \\
Cardiac disease & 2 & 3.84 \\
Anaemia & 1 & 1.92 \\
TB & 2 & 3.84 \\
Hepatitis B & 1 & 1.92 \\
Hepatitis E & 1 & 1.92 \\
Bronchial asthma & 2 & 3.84 \\
3) Antenatal care & & \\
Booked case & & \\
Unbooked case & 48 & 100 \\
& 0 & 0 \\
\hline
\end{tabular}

patients admitted in the postpartum period $(n=28,53.84 \%)$ were more than the antenatal admissions $(n=24,46.16 \%)$. $32.69 \%$ of admissions were in the third trimester.

The most common mode of delivery was emergency caesarean section $(n=27 / 40,67.5 \%)$. Total caesarean deliveries were $35 / 40=87.5 \%$ in ICU patients.

Seven $(n=7,13.46 \%)$ were medically managed and discharged (Table 2).

\subsection{ICU Data}

The mortality prediction scores were calculated for 41 patients only as acid blood gas analysis was not available for the rest of the patients.

\subsection{Interventions Undertaken in ICU}

Twenty seven (27) patients needed ventilation accounting for $51.92 \%$. 10 patients needed hemodialysis (19.23\%). 20 needed inotropic support. 26 patients needed blood transfusion (Tables 3 and 4).

\subsection{Statistical Analysis of ICU Parameters}

Analysis of the statistical data for ICU parameters has shown that hospital stay ( $p=0.011)$, and ventilation days $(p=0.014)$ are significant predictors of maternal outcome. Age $(p=0.789)$, ICU stay $(p=0.701)$ and RRT $(p$ $=0.632)$ are not significant. Frequency distribution of age, ICU stay, Hospital stay, Ventilation and RRT in relation to maternal outcome are shown in Figures $\mathbf{1}$ to $\mathbf{5}$.

The predicted mortality rate calculated as per APACHE2 score $(p=0.000)$, SOFA score $(p=0.000)$, SAPS2 score $(p=0.000)$, MPM0 score $(p=0.000)$ are statistically significant in relation to maternal outcome and all the 4 scores are equally predicting the mortality rate (Table 3 ).

The area of distribution under the ROC curve of all the scores was fair. The PMR AND ROC for APACHE II,
Table 2. Obstetric data.

\begin{tabular}{|c|c|c|c|}
\hline Sl No. & Characteristics & No. & $\%$ \\
\hline \multirow{4}{*}{1} & Antenatal admissions (Gravida status) & 24 & 46.16 \\
\hline & G1 & 09 & 37.5 \\
\hline & G2 & 04 & 16.66 \\
\hline & $\geq \mathrm{G} 3$ & 11 & 45.83 \\
\hline \multirow{4}{*}{2} & Postnatal admissions (Para status) & 28 & 53.84 \\
\hline & $\mathrm{P} 1$ & 11 & 39.28 \\
\hline & P2 & 12 & 42.85 \\
\hline & $\geq \mathrm{P} 3$ & 05 & 17.85 \\
\hline \multirow{5}{*}{3} & Gestation weeks & & \\
\hline & First trimester & 05 & 9.61 \\
\hline & Second trimester & 02 & 3.84 \\
\hline & Third trimester & 17 & 32.69 \\
\hline & Postpartum & 28 & 53.84 \\
\hline \multirow{6}{*}{4} & Mode of delivery & & \\
\hline & Normal vaginal delivery & 5 & 9.61 \\
\hline & Emergency LSCS & 27 & 51.92 \\
\hline & Elective LSCS & 8 & 15.38 \\
\hline & Emergency laparotomy & 5 & 9.61 \\
\hline & Medically managed cases & 7 & 13.46 \\
\hline
\end{tabular}

Table 3. Statistical analysis of ICU parameters.

\begin{tabular}{|c|c|c|c|}
\hline Variable & $\begin{array}{c}\text { Survival } \\
\text { (mean } \pm \text { SD) }\end{array}$ & $\begin{array}{c}\text { Death } \\
(\text { mean } \pm \text { SD) }\end{array}$ & $p$-value \\
\hline Age & $26.26 \pm 0.841$ & $26.85 \pm 0.27$ & 0.789 \\
\hline ICU stay & $4.31 \pm 0.42$ & $3.85 \pm 1.18$ & 0.701 \\
\hline Hospital stay & $7.51 \pm 0.514$ & $3.85 \pm 1.18$ & 0.011 \\
\hline Ventilation (days) & $1.28 \pm 0.35$ & $3.85 \pm 1.184$ & 0.014 \\
\hline RRT & $1.06 \pm 0.39$ & $0.42 \pm 0.29$ & 0.530 \\
\hline APACHE 2 score & $12.54 \pm 1.08$ & $33.83 \pm 2.66$ & 0.000 \\
\hline APACHE 2 PMR & $19.12 \pm 2.45$ & $77.31 \pm 6.09$ & 0.000 \\
\hline SOFA score & $5.25 \pm 0.714$ & $14.5 \pm 1.648$ & 0.000 \\
\hline SOFA PMR & $19.71 \pm 3.081$ & $70.00 \pm 7.746$ & 0.000 \\
\hline SAPS 2 score & $23.22 \pm 2.137$ & $74.33 \pm 6.474$ & 0.000 \\
\hline SAPS 2 PMR & $9.573 \pm 2.315$ & $82.13 \pm 7.71$ & 0.000 \\
\hline MPM 0 score & $-2.96 \pm 0.151$ & $1.636 \pm 0.941$ & 0.000 \\
\hline MPM 0 PMR & $6.857 \pm 1.484$ & $74.01 \pm 13.92$ & 0.000 \\
\hline MPM 24 score & $-3.117 \pm 0.185$ & $2.288 \pm 0.654$ & 0.000 \\
\hline MPM 24 PMR & $6.763 \pm 1.327$ & $86.46 \pm 7.262$ & 0.000 \\
\hline MPM 48 score & $-2.345 \pm 0.228$ & $3.820 \pm 0.693$ & 0.000 \\
\hline MPM 48 PMR & $14.39 \pm 3.09$ & $96.90 \pm 1.593$ & 0.000 \\
\hline MPM OVERTIME score & $-2.267 \pm 0.161$ & $2.863 \pm 0.256$ & 0.000 \\
\hline MPM OVERTIME PMR & $11.07 \pm 1.92$ & $94.28 \pm 1.476$ & 0.000 \\
\hline
\end{tabular}


Table 4. Interventions in ICU.

\begin{tabular}{cccc}
\hline SI No. & Intervention & No. & \% \\
\hline 1 & Arterial line & 42 & 80.76 \\
2 & Central venous catheter & 30 & 57.69 \\
3 & Inotropic support & 20 & 38.46 \\
4 & Blood transfusion & 26 & 50.00 \\
5 & Renal replacement therapy & 10 & 19.23 \\
6 & Mechanical ventilation & 27 & 51.92 \\
\hline
\end{tabular}



Figure 1. Frequency distribution of age in relation to maternal outcome.

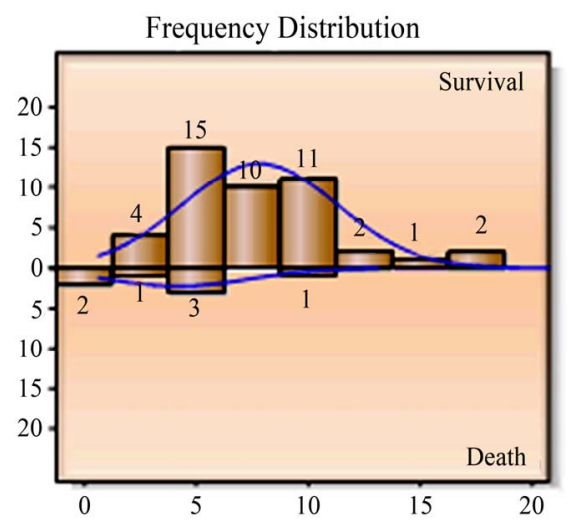

Figure 2. Frequency distribution of ICU stay.

\section{SOFA, SAPS II, MPMO are shown in Figures 6 to 13.}

\subsection{Indications for Obstetric Admission to ICU}

Among the obstetric ICU admissions, hypertensive disorders of pregnancy $(n=16,30.76 \%)$ was the predominant cause followed by obstetric haemorrhage $(n=12$, $23.07 \%$ ). Indirect causes accounted for $11 \%$. Non obstetric causes accounted for $13 \%$ (Table 5 ). The various surgical interventions undertaken in Obstetric ICU patients are shown in (Table 6).
Frequency Distribution

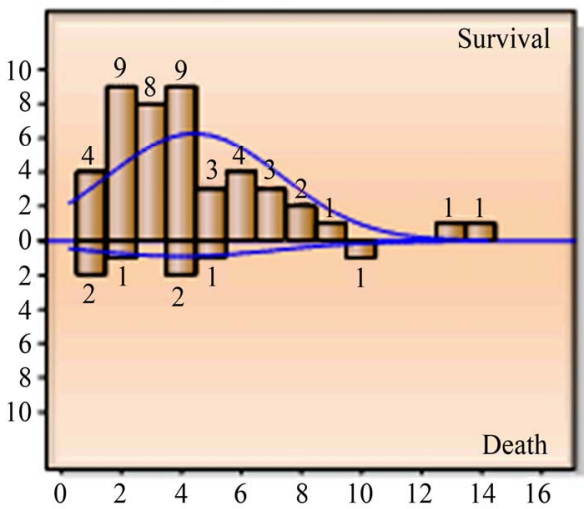

Figure 3. Frequency distribution of hospital stay.

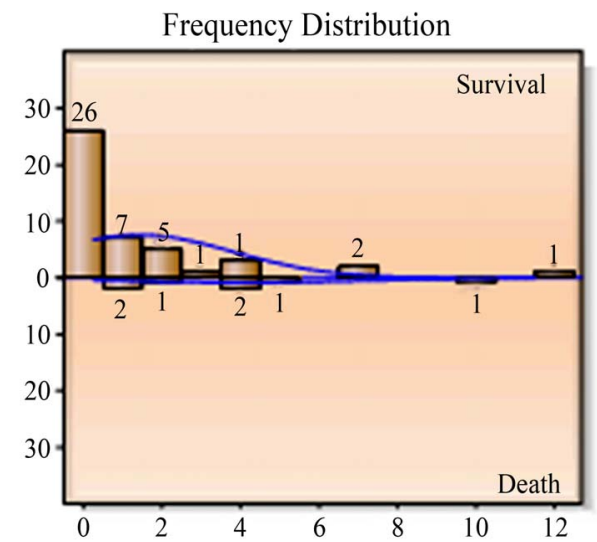

Figure 4. Frequency distribution for ventilation.

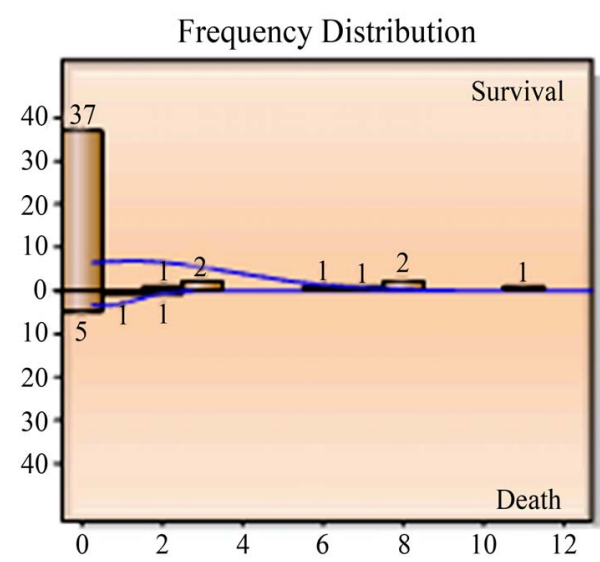

Figure 5. Frequency distribution for RRT.

\subsection{Perinatal Outcome}

The perinatal mortality rate was $21.42 \%(n=9)$, (Table 7) of 52 patients admitted in ICU, 40 patients delivered. Two patients delivered preterm twins. Of the remaining patients, two were admitted owing to complications following MTP, 6 were admitted and managed in antenatal 


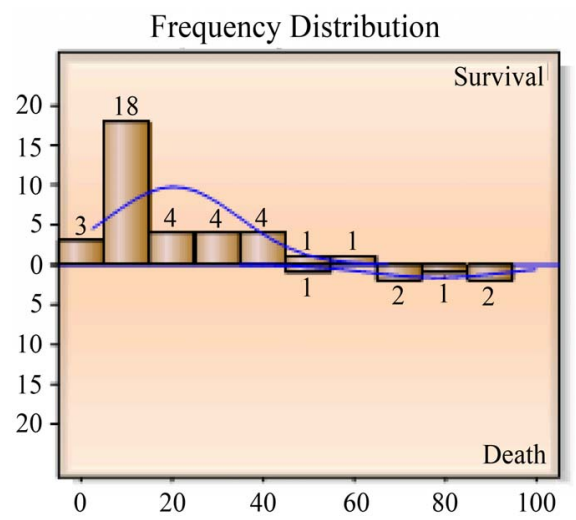

Figure 6. Apache 2 PMR.

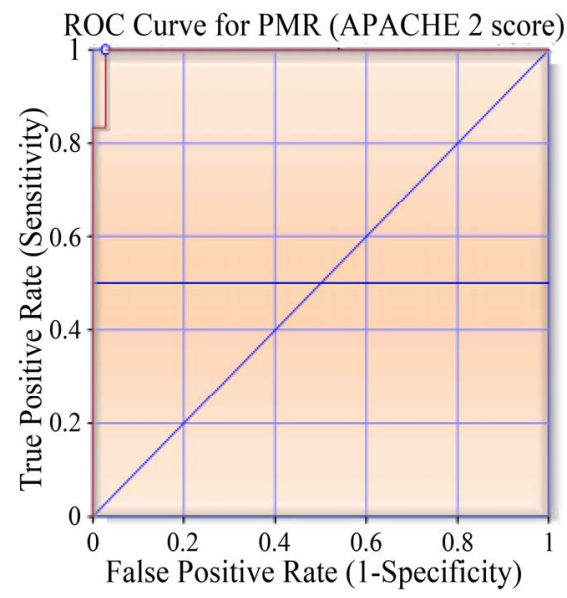

Figure 7. ROC curve (area under curve0.99524).

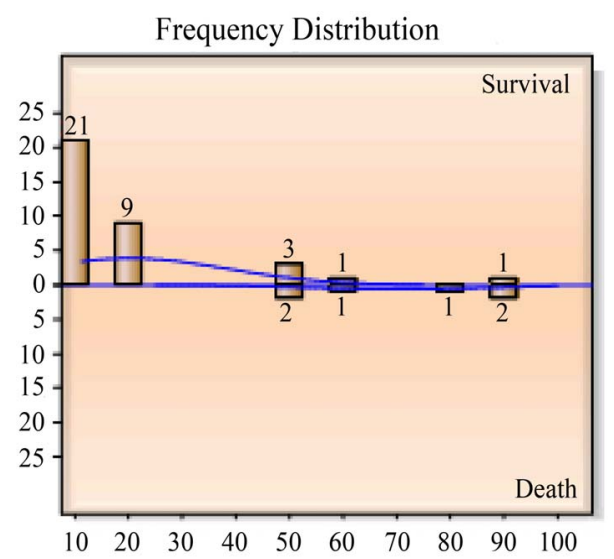

Figure 8. Frequency distribution of SOFA PMR.

period and discharged, 4 were managed actively following ruptured ectopic pregnancy.

\subsection{Maternal Deaths}

Of the 52 patients admitted, the number of maternal deaths was seven. Among maternal deaths in ICU obstet-

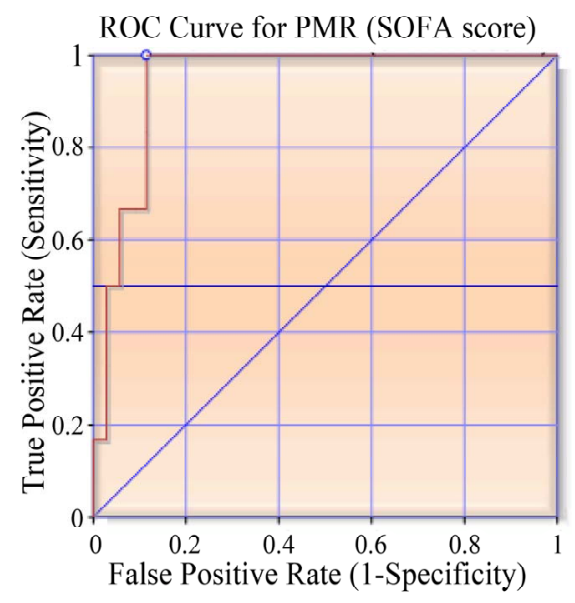

Figure 9. ROC curve (area under curve0.94286).

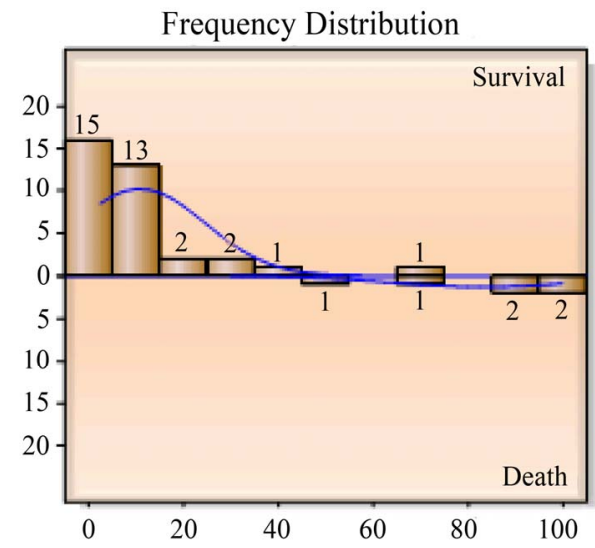

Figure 10. Frequency distribution of SAPS2 PMR.

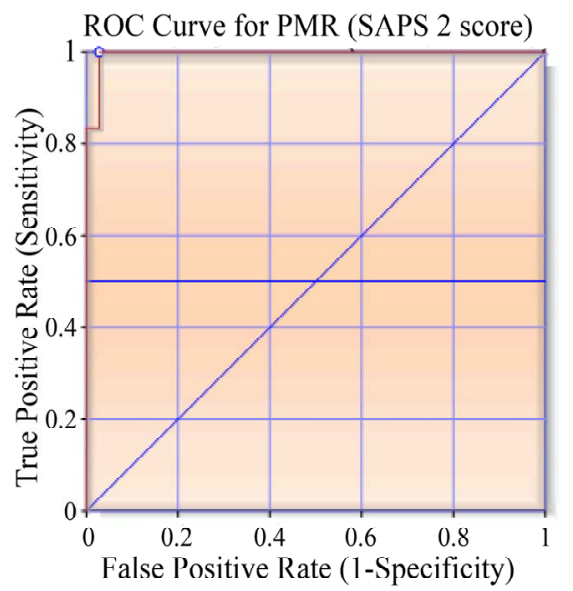

Figure 11. ROC curve (area under curve$0.99524)$.

ric admissions, pregnancy induced hypertension $(n=4$, $57 \%$ ) was the major cause. Anaesthesia related complications accounted for $29 \%(n=2)$. One $(14 \%)$ death was due to Eisenmenger's syndrome (Table 8). 


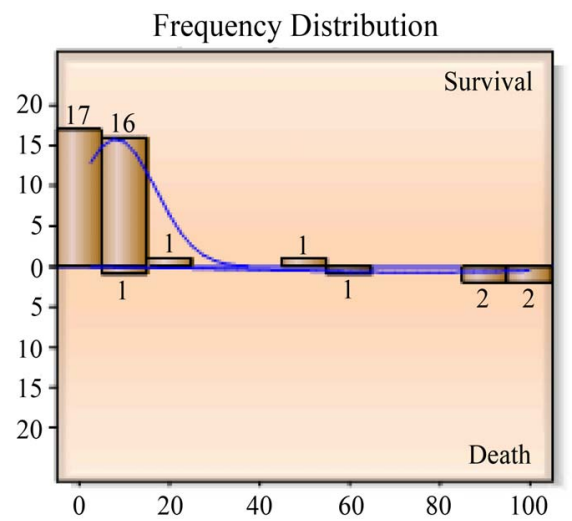

Figure 12. Frequency distribution MPM0 PMR.

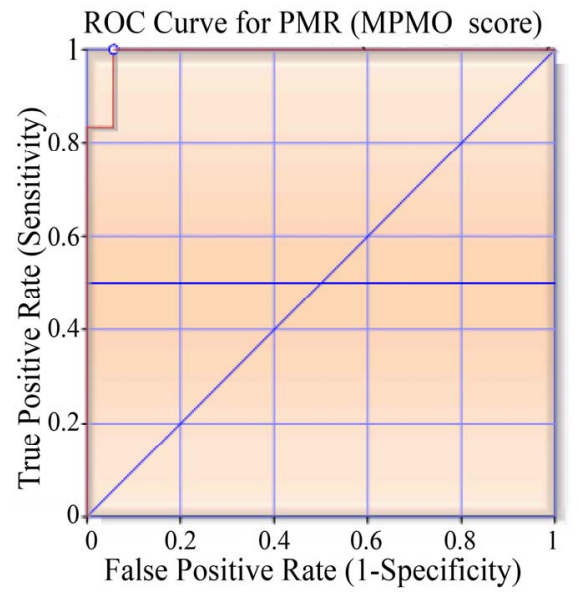

Figure 13. ROC curve (area under curve$0.99048)$.

\section{DISCUSSION}

The data presented in this series represents an overview of the spectrum of complications associated with pregnancy in a tertiary care corporate hospital.

In our study, the mean distribution of age of obstetric ICU patients was $26.34 \pm 5.34$ years. In studies conducted by Dilip R. Karnad et al. [10], the mean distribution of age was $25.5 \pm 4.6$ years and that done by Sunandagupta et al. was $25.21 \pm 4.075$ years, which were comparable to our study.

Most women ( $n=38,73.08 \%)$ who ultimately ended up in intensive care had no prior risk factors except 14 patients (26.92\%) who had the associated comorbidities. Thyroid disorders seem to be the most common comorbid associations in this data set. This is probably consistent with the overall prevalence of thyroid dysfunction in the community. Cardiac disease and asthma were the next most common associations.

Our hospital being a tertiary care centre, majority of the admissions in ICU in our study were referrals from the other multispecialty hospitals, private nursing homes
Table 5. Obstetric indication of ICU admission.

\begin{tabular}{|c|c|c|c|}
\hline Sl no & Diagnosis & No. & $\%$ \\
\hline & Direct causes & & \\
\hline \multirow{7}{*}{ 1) } & Haemorrhage: & 12 & 23.07 \\
\hline & Postpartum haemorrhage & 4 & \\
\hline & Uterine rupture & 1 & \\
\hline & Antepartum haemorrhage & & \\
\hline & Abruptio placenta & 2 & \\
\hline & Placenta praevia & 1 & \\
\hline & Ruptured ectopic & 4 & \\
\hline 2) & Sepsis & 4 & 7.69 \\
\hline 3) & Unsafe abortion & 1 & 1.92 \\
\hline \multirow[t]{4}{*}{ 4) } & Hypertensive disorders: & 16 & 30.76 \\
\hline & Pre eclampsia & 2 & \\
\hline & HELLP syndrome & 9 & \\
\hline & Eclampsia & 5 & \\
\hline 5) & Obstructed labour & 0 & \\
\hline \multirow[t]{5}{*}{$6)$} & Other: & & \\
\hline & Embolism & 3 & 5.76 \\
\hline & Anaesthesia related & 2 & 3.84 \\
\hline & OHSS with pregnancy & 1 & 1.92 \\
\hline & Indirect causes & & \\
\hline 7) & Hematological disorders & 1 & 1.92 \\
\hline \multirow[t]{4}{*}{ 8) } & Cardiac diseases & 5 & 9.61 \\
\hline & CRHD & 1 & \\
\hline & PPCM & 3 & \\
\hline & Eisenmenger's syndrome & 1 & \\
\hline 9) & Diabetes & 0 & \\
\hline 10) & Thyroid disorders & 0 & \\
\hline \multirow[t]{2}{*}{ 11) } & Viral hepatitis & & \\
\hline & Hepatitis E & 1 & \\
\hline \multirow[t]{5}{*}{ 12) } & Non obstetric causes & & \\
\hline & Dengue & 2 & 3.84 \\
\hline & Community acquired pneumonia & 3 & 5.76 \\
\hline & Pulmonary Kochs & 1 & 1.92 \\
\hline & H1N1 & 1 & 1.92 \\
\hline
\end{tabular}

in our city. We observed from our study that almost all the patients were booked cases having regular antenatal care prior to admission, but still had not missed the grave emergency situations. This observation emphasizes that most obstetric emergencies are unpredictable and routine out-patient based antenatal care may not always prevent all the maternal deaths. Thus it is the combination of vigilant antenatal care and intensive obstetric care that is essential for reducing maternal mortality.

According to Sample Registration System of Registrar General of India (2006) [11], 55\% maternal deaths take place during the postpartum period, $20 \%$ during delivery and $25 \%$ during pregnancy. Similarly in our study, we observed that almost $53.84 \%(n=28)$ of our patients in ICU were admitted in the postpartum period. This is comparable to other studies conducted by Sunandagupta et al. [12], i.e. $83.33 \%$, Daniele N. Vasquez et al. [5], i.e. $63 \%$ and $\mathrm{Ng}$ et al. [13] i.e. $97 \%$. It is not commonly realized that so many complications can occur in the postpartum period. In obstetrics, delivery being the key event, the complications would be either intrapartum or postpartum and postpartum admissions and referrals would be maximum. The anaesthetic mishaps, $\mathrm{PPH}$, the need 
Table 6. Emergency surgical interventions in obstetric ICU patients.

\begin{tabular}{|c|c|c|c|}
\hline S1 No. & Indication & Surgery & No. \\
\hline 1 & $\begin{array}{l}\text { Hemoperitoneum } \\
\text { due to HELLP, DIC }\end{array}$ & Laparotomy after LSCS & 2 \\
\hline 2 & $\begin{array}{l}\text { Hemoperitoneum } \\
\text { post LSCS }\end{array}$ & $\begin{array}{c}\text { Laparotomy and evacuation } \\
\text { of large left broad } \\
\text { ligament hematoma }\end{array}$ & 1 \\
\hline 3 & $\begin{array}{l}\text { Post second trimester } \\
\text { abortion, surgical } \\
\text { placental removal }\end{array}$ & $\begin{array}{l}\text { Laparotomy for uterine } \\
\text { rupture repair, and ligation of } \\
\text { a bleeder from Iliac vessels. }\end{array}$ & 1 \\
\hline 4 & Atonic $\mathrm{PPH}$ & $\begin{array}{l}\text { Post LSCS peripartum } \\
\text { hysterectomy }\end{array}$ & 1 \\
\hline \multirow{2}{*}{5} & $\begin{array}{c}\text { Dengue } \\
\text { THROMBOCYTOPENIA }\end{array}$ & $\begin{array}{l}\text { Abdominal wall hematoma } \\
\text { evacuation }\end{array}$ & 1 \\
\hline & HELLP, DIC & $\begin{array}{l}\text { Abdominal wall hematoma } \\
\text { evacuation }\end{array}$ & 1 \\
\hline 6 & Secondary PPH & $\begin{array}{l}\text { Evacuation of retained } \\
\text { placental bits }\end{array}$ & 1 \\
\hline 7 & $\begin{array}{l}\text { Ruptured ovarian cyst in } \\
\text { post partum period, sepsis }\end{array}$ & Laparotomy \& ovariectomy & 1 \\
\hline 8 & $\begin{array}{l}\text { Ruptured ectopic } \\
\text { pregnancy in shock }\end{array}$ & Laparotomy \& salpingectomy & 4 \\
\hline 9 & Swine flu & Tracheostomy & 1 \\
\hline 10 & $\begin{array}{l}\text { Secondary PPH due to } \\
\text { anticoagulants-increased } \\
\text { INR }\end{array}$ & Medical management & 1 \\
\hline
\end{tabular}

Table 7. Perinatal outcome.

\begin{tabular}{cccc}
\hline SL No. & Perinatal outcome & No. & \% \\
\hline 1$)$ & Live term & 23 & 54.76 \\
$2)$ & IUD & 3 & 7.14 \\
$3)$ & Still birth & 4 & 9.52 \\
$4)$ & Neonatal deaths & 2 & 4.76 \\
$5)$ & IUGR & 1 & 2.38 \\
$6)$ & Preterm & 9 & 21.42 \\
& Total & 42 & \\
\hline
\end{tabular}

for hysterectomy and the need for blood products would be at the time of delivery. Better obstetric care in this period would prevent some of these complications.

In our study, obstetric patients admitted in the antenatal period accounted for $46.16 \%(n=24)$. Out of these maximum number $(n=17,32.69 \%)$ were admitted in the third trimester, $3.84 \%(n=2)$ in second trimester and $9.61 \%(n=5)$ in the first trimester. These aspects of gestational age highlight the maximum occurrence of complications in the third trimester and postpartum period \& thus the importance of close supervision of patients during these periods [14].
Table 8. Causes of maternal deaths.

\begin{tabular}{ccc}
\hline Sl No. & Primary diagnosis & Cause of death \\
\hline 1 & HELLP & DIC \\
2 & HELLP & DIC \\
3 & High spinal shock & HIE \\
4 & HELLP, hepatitis E positive & MODS \\
5 & Eclampsia & Massive intracranial \\
& hemorrhage \\
6 & High spinal shock & HIE \\
7 & Eisenmenger's syndrome & Cardiac failure \\
\hline
\end{tabular}

Other studies by Abdulaziz Aldawood [15] (PIH28\%), Tuncer Simsek et al. [16] (PIH—65.1\%), Faponle $\mathrm{AF}$ et al. [17] (PIH-58.8\%), Daniele N. Vasqez et al. [5] (PIH-40\%), Fernando G Rios et al. (PIH-71.69\%) [18] have shown that PIH, obstetrical hemorrhage and medical disorders of the pregnancy were the most common indications requiring transfer to ICU. The findings in our study (PIH-30.76\%) were comparable to the above studies $[5,15]$.

There was also one case $(1.92 \%)$ of H1N1 who was admitted in ICU with ARDS. To combat the respiratory failure, she was on mechanical ventilator. But owing to worsening respiratory distress and having no chance of weaning from ventilator even for shifting to emergency theatre, caesarean section was done in MICU and preterm baby delivered. This incident is supported by Recommendation of ACOG [19] Caesarean delivery in the ICU should be restricted to cases where transport to the operating room or delivery room cannot be achieved safely or expeditiously or to a perimortem procedure.

Globally, an estimated 287,000 maternal deaths occurred in 2010. Sub-Saharan Africa (56\%) and Southern Asia $(29 \%)$ accounted for $85 \%$ of the global burden (245,000 maternal deaths). Of these, 56,000 maternal deaths $(19 \%)$ occurred in India making it one of the two countries, Nigeria at $14 \%(40,000)$, accounting for a third of global maternal deaths in 2010. Trends in maternal mortality: 1990 to 2010 WHO, UNICEF, UNFPA and The World Bank estimates; WHO 2012) [20]. The most recent MMR estimates of India by the Public System are available for the period 2007-2009 (SRS 2011), which is 212 per 100,000 live births, which translates into an approximate number of 56,000 maternal deaths in one year.

\section{Maternal Deaths: Seven Cases}

A primi with 30 weeks gestation and eclampsia complicating pregnancy with massive intracranial haemorrhage was admitted in a comatose state, she was declared brain dead at admission. But emergency caesarean section was 
done for fetal salvage, preterm twins were delivered, admitted in NICU and could be saved. Thus, this is an example of perimortem caesarean delivery.

Two patients died due to high spinal shock, they were brain dead at admission. So no question of survival and were unavoidable deaths at this hospital. These were 2 cases of maternal death due to anaesthetic accidents.

One patient with hepatitis E and HELLP syndrome had cardiac arrest in emergency room and could not be revived and she was not admitted to ICU.

Two patients had HELLP syndrome with DIC who could not be saved. The case of Eisenmenger syndrome should have avoided pregnancy as per the advice given to her.

The maternal mortality in this series of cases was $7 / 52$ $=13.46 \%$. Excluding the unavoidable cases of maternal death ( 3 cases brain dead at admission and one cardiac arrest in emergency room), our maternal mortality rate is $3 / 48=6.25 \%$. The maternal deaths $189 / 754(25 \%)$ [4] and 98/453 (21.6\%) [7] have been reported in ICU patients in Indian studies.

In our study, perinatal death rate was $21.42 \%(n=9)$, three $(7.14 \%)$ were intrauterine deaths, four $(9.52 \%)$ were stillbirths, two $(4.76 \%)$ were neonatal deaths.

The mean length of ICU stay was $4.2 \pm 2.38$ days which are comparable to studies done by Jose Orsini et al. [21], 3.5 days and Anjali Tempe et al. [11], 3.4 days. In our study, the mean length of ventilation was $3.2 \pm 2.8$ days. Twenty seven patients $(n=27,51.92 \%)$ required support of mechanical ventilation. This is comparable to the studies by Natalie YW Leung et al. [22], Daniele N. Vasquez et al. [5] where the requirement was for $58 \%$ and $41 \%$ patients respectively.

The most common procedure required by the cohort was arterial access $(n=42,80.76 \%)$, reflecting the incidence of hemodynamic instability as the presenting feature in a significant percentage of this group. The need to administer vasoactive agents to optimize the hemodynamics is reflected in the necessity for central venous access $(n=30,57.69 \%)$ Respiratory failure is another reason for admission to ICU. Twenty patients required inotropic support $(n=20,38.46 \%)$, blood products for $26(50 \%)$ patients. Hemodialysis was done in $10(19.23 \%)$ patients. However, the ROC curves seem to suggest that these interventions per se were not predictors of severity or indications of outcomes among this subset.

Analysis of ICU data suggests that mortality occurs within the first week. Most of the non survivors succumbed to their illness within the first week. Going by the severity scoring systems, this early mortality is probably due to the overall severity rather than the futility of intensive care. Amongst the interventions done for these patients mechanical ventilation seems to have an influence on the overall outcome. Analysis of the data seems to suggest that need for ventilator support beyond the 5th day is associated with higher number of deaths. This is again a reflection of the severity of the organ failure rather than a complication of mechanical ventilation.

The predicted mortality as measured by all scoring systems (for 41 patients) was between $17 \%-30 \%$. The observed mortality was around $17 \%$. The MPM0 yielded the least PMR while the SAPS 2 score predicted a higher mortality. However the ROCs of all the scoring systems revealed a good correlation. The predicted mortality rates calculated by APACHE2, SOFA, SAPS2, MPM scoring systems were statistically significant in this study. In a retrospective review by El-Solh AA et al. [23] the predictive ability of APACHE2, SAPS2, and MPM2 scores in critically ill obstetric patients was evaluated and compared to a control group of non-obstetric female patients of similar age groups, who were admitted to ICUs, the observed mortality was not statistically different from the mortality predicted by these scores for the obstetric group and non-obstetric group and predictive accuracy of these models as assessed by the c-index, which is equivalent to the area under the ROC curve has been proved.

The overall reduction in mortality of about $40 \%$ reflects the benefit of early identification of this subset of patients and timely initiation of intensive care.

\section{CONCLUSIONS}

This study demonstrated the clinical characteristics and maternal outcomes of the obstetric patients admitted to ICU. Leading cause of maternal mortality was HELLP syndrome. Hypertensive disorders of pregnancy are the most common causes of admission to ICU. Prolongation of pregnancy for fetal salvage by expectant management in pre-eclampsia should not be continued for too long a period, lest complications leading to maternal mortality would occur.

Salvaging the pregnant woman should take precedence over fetal salvage. The Hypitat trial [24] recommends delivery by 36 completed weeks even for cases of mild preeclampsia, so as to avert severe preeclampsia, eclampsia, and HELLP syndrome and abruptio placenta in the last four weeks of gestation.

Accurate predictive scores in the ICUs apart from providing aggressive management in those predicted for a poor outcome, could also lead to better productive utilization of the limited resources. A better scoring system especially applicable to the critically ill obstetric patients in the Indian scenario could lead to accurate monitoring of quality care and risk stratification for clinical and therapeutic trials. In this study all the scores were equally significant in predicting maternal mortality. The scoring system that can easily be adopted like SOFA score should be taught, practised and be incorporated into pro- 
tocols/guidelines. Obstetric ICU facility should be available in large maternity centres and in each or every district of India.

Amongst the interventions done for these patients mechanical ventilation seems to have an influence on the overall outcome. Analysis of the data seems to suggest that need for ventilator support beyond the 5th day is associated with higher number of deaths.

\section{ACKNOWLEDGEMENTS}

We sincerely thank the CMD-Dr. B. Soma Raju and the Dean of CIMS, Dr. Raja Gopala Raju for their cooperation and for permitting the hospital data to be sent for publication.

\section{REFERENCES}

[1] (1992) International statistical classification of diseases and related health problems. 10th Rev, Vol. 2, World Health Organization, Geneva, 98-99.

http://www.who.int/classifications/icd/ICD-10 2nd ed v olume2.pdf

[2] Ministry of Health and Family Welfare (2011) NRHM health management Information system (HMIS) portals. http://www.censusindia.gov.in/vital_statistics/SRS_Bullet ins/Final-MMR\%20Bulletin-2007-09 070711.pdf

[3] Soubra, S.H. and Guntupalli, K.K. (2005) Critical illness in pregnancy: An overview. Critical Care Medicine, 33, S248-S255.

http://dx.doi.org/10.1097/01.CCM.0000183159.31378.6A

[4] Karnad, D.R. and Guntupalli, K.K. (2004) Critical illness and pregnancy: Review of a global problem. Critical Care Clinics, 20, 555-576. http://dx.doi.org/10.1016/j.ccc.2004.05.001

[5] Vasquez, D.N., Estenssoro, E., Canales, H.S., Reina, R., Saenz, M.G., Das Neves, A.V., Toro, M.A. and Loudet, C.I. (2007) Clinical characteristics and outcomes of obstetric patients requiring ICU admission. Chest, 131, 718724. http://dx.doi.org/10.1378/chest.06-2388

[6] Al-Suleiman, S.A., Qutub, H.O., Rahman, J. and Rahman, M.S. (2006) Obstetric admissions to the intensive care unit: A 12 year review. Archives of Gynecology and $\mathrm{Ob}$ stetrics, 274, 4-8.

http://dx.doi.org/10.1007/s00404-004-0721-Z

[7] Munnur, U., Karnad, D.R., Bandi, V.D., Lapsia, V., Suresh, M.S., Ramshesh, P., et al. (2005) Critically ill obstetric patients in an American and an Indian public hospital: Comparison of case mix organ dysfunction, intensive care requirements and outcomes. Intensive Care Medicine, 31, 1087-1094. http://dx.doi.org/10.1007/s00134-005-2710-5

[8] Tempe, A., Wadhwar, L., Gupta, S., Bansal, S. and Satyanarayana, L. (2007) Prediction of mortality and morbidity by simplifies acute physiology score (SAPS II) in obstetric ICU admissions. Indian Journal of Medical Sciences, 61, 179-185.

http://dx.doi.org/10.4103/0019-5359.31151

[9] Vincent, J.L., Mendonca, A. and Cantraine, F. (1998) Use of the SOFA score to assess the incidence of organ dysfunction/failure in intensive care units: Results of a multicenter, prospective study. Critical Care Medicine, 26, 1793-1800.

http://dx.doi.org/10.1097/00003246-199811000-00016

[10] Karnad, D.R., Lapsia, V., Krishnan, A. and Salvi, V.S. (2004) Prognostic factors in Obstetric patients admitted to an Indian intensive care unit. Critical Care Medicine, 32, 1294-1299.

http://dx.doi.org/10.1097/01.CCM.0000128549.72276.00

[11] Govt. of India (Sample Registration System) (2006) Maternal mortality in India: 1997-2003. Trends, causes and risk factors, registrar general, India, New Delhi in collaboration with Centre for Global Health Research University of Toronto, Canada.

[12] Gupta, S., Naithani, U., Doshi, V., Bhargava, V. and Vijay, B.S. (2011) Obstetric critical care: A prospective analysis of clinical characteristics, predictability and fetomaternal outcome in a new dedicated obstetric intensive care unit. Indian Journal of Anaesthesia, 55, 146-153. http://dx.doi.org/10.4103/0019-5049.79895

[13] Ng, V.K., Lo, T.K., Tsang, H.H., Lau, W.L. and Leung, W.C. (2013) Intensive care unit admission of obstetric cases: A single centre experience with contemporary update. Hong Kong Medical Journal. www.hkmj.org

[14] Bhadade, R., de' Souza, R., More, A. and Harde, M. (2012) Maternal outcomes in critically ill obstetrics patients: A unique challenge. Indian Journal of Critical Care Medicine, 16, 8-16. http://dx.doi.org/10.4103/0972-5229.94416

[15] Aldawood, A. (2011) Clinical characteristics and outcomes of critically ill obstetric patients: A ten year review. Annals of Saudi Medicine, 31, 518-522. http://dx.doi.org/10.4103/0256-4947.84631

[16] Simsek, T., Eyigor, C., Uyar, M., Karaman, S. and Moral, A.R. (2011) Retrospective review of critically ill obstetrical patients: A decade's experience. Turkish Journal of Medical Sciences, 41, 1059-1064.

[17] Faponle, A.F. and Adenekan, A.T. (2011) Obstetric admissions into the intensive care unit in a sub-urban University Teaching Hospital. Nepal Journal of Obstetrics and Gynaecology, 6, 33-36.

[18] Rios, F.G., Risso-Vazquez, A., Alvaez, J., Vinzio, M., Falbo, P., Rondinelli, N. and Bienzobas, D.H. (2012) Clinical characteristics and outcomes of obstetric patients admitted to the intensive care unit. International Journal of Gynecology \& Obstetrics India, 15, 430-434.

[19] American College of Obstetricians and Gynaecologists (ACOG) (2009) Critical care in pregnancy. Washington DC: American College of Obstetricians and Gynaecologists.

[20] WHO (2012) Trends in maternal mortality: 1990 to 2010 WHO, UNICEF, UNFPA and The World Bank estimates.

[21] Orsini, J., Butala, A., Diaz, L., Muzylo, E., Mainardi, C. and Kestell, P. (2012) Clinical profile of obstetric patients admitted to the Medical Surgical Intensive Care Unit (MSICU) of an Inner-City Hospital in New York. Journal of Clinical Medicine Research, 4, 314-317.

[22] Leung, N.Y., Lau, A.C., Chen, K.K. and Yan, W.W. 
(2010) Clinical characteristics and outcomes of obstetric patients admitted to the Intensive Care Unit: A 10 year retrospective review. Hong Kong Medical Journal, 16, $18-25$.

[23] El-Sohl, A.A. and Grant, B.J. (1996) A comparison of severity of illness scoring systems for critically ill obstetric patients. Chest, 110, 1299-1304.

http://dx.doi.org/10.1378/chest.110.5.1299
[24] Koopmans, C.M., Bijlenga, D., Groen, H., Vigen, S.M., Aarnoudse, J.G., for the HYPITAT Study Group (2009) Induction of labour versus expectant monitoring for gestational hypertension or mild pre-eclampsia after 36 weeks gestation (HYPITAT): A multicentre, open label randomized controlled trial. Lancet, 374, 979-988. http://dx.doi.org/10.1016/S0140-6736(09)60736-4 